\title{
A ideia de socialismo: Tentativa de Atualização
}

The Idea of Socialism: Towards a Renewal

\begin{abstract}
HONNETH, Axel. A Ideia de Socialismo: Tentativa de Atualização. Lisboa: Edições 70, 2017.
\end{abstract}

Enrico Paternostro Bueno da Silva ${ }^{1}$

A publicação de O Direito da Liberdade (Das Recht der Freiheit), por Axel Honneth em 2011, suscitou uma série de debates entre os estudiosos da justiça social comprometidos com o projeto de uma Teoria Crítica. Foi apontado, de sobremaneira, que o argumento apresentava alguma tendência conservadora, na medida em que propunha teorizar acerca dos caminhos para a realização da liberdade sob os parâmetros institucionais atualmente existentes; o modelo ofereceria, grosso modo, pouco ou nenhum espaço para se pensar momentos de ruptura ou transfiguração social. O livro em tela, originalmente publicado em 2015 como Die Idee des Sozialismus e traduzido à língua portuguesa em 2017, aparece com a tarefa explícita de suprir aquela lacuna e expandir o horizonte normativo formulado anteriormente para além do modelo atualmente vigente de democracia liberal capitalista.

Da obra anterior, mantém-se principalmente seu princípio fundamental à justiça social moderna: a liberdade social. Ele deriva de certa interpretação da Filosofia do Direito de Hegel e aparece para expressar que tal entendimento da moderna concepção de liberdade é o mais propício à emancipação dos sujeitos. Sucintamente, o argumento subjacente defendido pelo autor indica que

os sujeitos individuais só podem realizar a sua capacidade para a liberdade enquanto membros de uma comunidade social, a qual, por seu lado, tem de ser, contudo, livre no sentido em que a concretização

\footnotetext{
${ }_{1}$ Doutorando no Programa de Pós-Graduação em Sociologia da Universidade Estadual de Campinas, com pesquisa financiada pela Capes. Contato: enricobuenodasilva@gmail.com. Campinas-SP.
} 
recíproca das intenções partilhadas pela generalidade ocorre sem coerção e, portanto, numa atitude de simpatia reciproca. (HONNETH, 2017, p. 47).

Se em O Direito da Liberdade, Honneth formula um longo argumento filosófico para defender essa compreensão da liberdade em face das concepções liberais ("liberdade negativa", conforme Hobbes e Nozick) e morais ("liberdade optativa", conforme Kant e Habermas), em A Ideia de Socialismo seu trabalho consiste em demonstrar como essa perspectiva já estava presente nos primeiros socialistas do século XIX, de modo a apontar os principais limites de seus projetos e alguns caminhos possiveis para sua superação contemporânea. São tomados como referenciais para o estudo os modelos de Robert Owen, SaintSimon, Fourier e, com evidente destaque, Karl Marx e Friedrich Engels.

Seguindo sua habitual estratégia argumentativa, inspirada na filosofia hegeliana, Honneth organiza o texto em três passos: um primeiro dedicado a apresentar a ideia de socialismo como projeto político fundamentado sobre o princípio da liberdade social; um segundo voltado às limitações centrais da compreensão que se desenvolveu no século XIX, ainda influente sobre movimentos políticos; e um terceiro que visa pensar "caminhos de renovação", de modo que o subsistente vigor do socialismo possa encaminhar mudanças sociais condizentes com a ampliação da liberdade social. Essa última etapa é subdividida em dois capitulos, nos quais são apresentadas duas propostas centrais para a "renovação": a concepção de socialismo como experimentalismo histórico e a expansão da liberdade social para além da esfera econômica.

O apontamento inicial de Honneth quanto à ideia de socialismo indica que esta sempre se referiu a uma crítica imanente à ordem social moderna, na qual seus fundamentos legitimadores (liberdade, igualdade e fraternidade) são contrastados com sua estrutura social e seus mecanismos reprodutores. O resultado, em linhas gerais, foi a constatação de que seus três princípios fundamentais não poderiam ser articulados sob a concepção individualista de liberdade, socialmente necessária à dinâmica do sistema vigente. Tratava-se, portanto, de construir um modelo de sociedade que lograsse articular liberdade e solidariedade, superando-se as contradições postas por uma conceituação estritamente liberal. Em face disso, Honneth inicialmente analisa as propostas teóricas daqueles autores, apontando que eles se esquivaram da discussão sobre 
a participação política democrática - quando não a negaram precipitadamente -, de modo a restringir o rico conceito de liberdade social nascente ao âmbito da esfera econômica da produção de mercadorias. Ademais, a pretensão históricometafisica dos primeiros socialistas "haveria de tornar quase impossivel entender os próprios avanços como testes experimentais da mutabilidade das sociedades capitalistas" (idem, ibidem, p. 44).

Após o segundo momento da obra - em que o autor investiga como a "cultura do industrialismo" reduziu a discussão à esfera econômica (desprezando de saída os avanços logrados pelos direitos liberais de cidadania) e a filosofia hegeliana da história inspirou teses teleológicas sobre a inevitabilidade do socialismo -, os dois últimos capítulos apresentam caminhos de atualização da ideia de socialismo, de modo a fazê-lo compativel com as condições históricas contemporâneas e livre dos déficits originais. São muitos os elementos que atravessam essa proposta de renovação, os quais compreendem, de modo convergente com o que se lê em Direito da Liberdade, a necessidade de abranger "as necessidades partilhadas de intimidade fisica e emocional” (idem, ibidem, p. 148), bem como a formação pública e democrática da vontade, sob o conceito de liberdade social. A principal novidade do texto de 2015, entretanto, é a concepção experimental de socialismo.

Para chegar a ela, Honneth propõe superar a equação marxiana entre economia de mercado e capitalismo. Exemplifica a variedade histórica de possibilidades de "mercados" com três tipos ideais: a "mão invisivel" idealizada por Adam Smith, segundo o qual os interesses complementares dos cidadãos garantiriam uma satisfação recíproca das necessidades mediada pela lei de oferta e procura; a fundamentação da produção e intercâmbio de mercadorias sobre “associações de produtores livres”, autogestionados democraticamente, segundo principios da sociedade civil; e uma economia centralizada no Estado, encarregado de supervisionar a produção e reprodução econômica de modo a garantir o maior bem-estar possivel aos seus cidadãos. Entendendo que nenhum dos três modelos de "economia de mercado" coincide com a economia capitalista contemporânea, Honneth propõe não rejeitar a priori as contribuições de cada qual à ampliação das possibilidades de liberdade social no plano econômico. Dessa forma, e contrariando as premissas histórico-filosóficas dos primeiros 
socialistas, o autor indica que a implementação institucional do socialismo deve passar por experiências que não descartem intuições ricas alcançadas pelos três modelos.

Daí seu conceito de socialismo experimental ou, conforme o autor intitula seu terceiro capítulo, o socialismo como experimentalismo histórico. Retomando a noção de imanência característica do Direito da Liberdade, Honneth compreende que a possibilidade de concreção histórica do socialismo deve passar pela superação tanto de sua ideia enquanto teoria da justiça puramente normativa que, a seu ver, caracterizou o marxismo analítico - quanto de uma perspectiva histórico-teleológica que considera uma sequência necessária de mudanças sociais derivadas do desenvolvimento inevitável das forças produtivas. Do contrário, o autor encara o socialismo como fundado na existência histórica de grupos, sempre renovados conforme as circunstâncias sócio-históricas, "que se esforçam para que suas próprias reivindicações, não atendidas até ao momento, sejam ouvidas em público, procurando derrubar as barreiras na comunicação e, por conseguinte, alargando os espaços de manobra da liberdade social" (idem, ibidem, p. 92-93).

O epíteto caracterizador de seu conceito de liberdade é fundamental para entender tanto seu conceito de socialismo quanto a perspectiva de justiça social que poderá ser dele derivada. Ao tratar o socialismo como "direito ao social", Honneth quer apontar a existência, nas sociedades modernas, de um “desejo generalizado de eliminar todos os obstáculos sociais que poderiam impedir a prática da liberdade numa ação recíproca de solidariedade” (idem, ibidem, p. 94). O "social", portanto, se caracterizaria pela comunicação mais alargada possivel dos membros da sociedade, a ponto de conseguir originar uma nova tendência histórica no seio da própria realidade imediata em que os membros se encontram. Dessas novas considerações honnethianas, pode-se depreender um conceito de justiça social ainda mais sintético do que aquele trazido pelo Direito da Liberdade: ele se refere ao conjunto de mudanças processuais institucionais (em sentido lato), possíveis ou em atuação, que se dão no sentido de ampliar as possibilidades comunicativas entre os sujeitos, de modo a respaldar e favorecer a consolidação de padrões intersubjetivos de reconhecimento recíproco e de precondições objetivas à autorrealização de cada um. 
Seguindo a ideia revigorada de socialismo pela qual Honneth advoga, tais mudanças processuais, como não aparecem como historicamente necessárias, não poderão resultar apenas de exercícios intelectuais, mas devem se sujeitar a experimentações sociais. Na esfera econômica, em que a ideia de socialismo foi sempre mais forte, o autor concebe que isso se traduziria em uma série de modelos ensaiados intelectualmente (do "socialismo de mercado" à "Renda Básica Universal”) para responder a uma das questões fundamentais da concretização do socialismo: a de se saber se o melhor caminho à emancipação dos trabalhadores exige primeiramente sua associação coletiva à propriedade, juridicamente expropriada do Capital, ou a manutenção temporária das formas de propriedade existentes associada a politicas que impliquem na perda gradual do controle Capital sobre o trabalho.

Embora as ponderações e hipóteses intelectualmente formuladas sejam de suma importância às teorias socialistas, Honneth entende que respostas como essa só serão alcançadas mediante "uma conquista permanente e árdua de espaços de liberdade e de nichos sociais que permitam testar, em condições reais e respeitando o princípio de preservação das práticas já comprovadas (...), que modelos alternativos nos aproximam mais do objetivo imediato que se pretende atingir" (idem, ibidem, p. 100). Recorrendo a estudos de Erik Olin Wright, o autor demonstra a existência de iniciativas de tal tipo (como cooperativas de produção autogestionadas e fundos solidários de trabalhadores) que, do ponto de vista de uma perspectiva de construção do socialismo, precisariam encontrar mais espaços de experimentação.

A experimentação socialista, portanto, pode ser entendida enquanto mediação politica entre a configuração sócio-institucional dada e uma nova realidade passivel de vir-a-ser; movimento que, conforme versa o pensamento dialético marxiano, resulta das contradições internas gestadas no seio do modo de produção totalizante vigente. $\mathrm{O}$ autor, claramente, não restringe esse salto ao âmbito da economia política; contudo, no que tange a este, a obra traz notável revisão: se o texto de Luta por Reconhecimento se furta a discutir a compatibilidade entre a "vida ética" e o "capitalismo", e o de Direito da Liberdade aparenta restringir as possibilidades de ampliação da justiça sob os termos das democracias liberais burguesas, o argumento de A Ideia de Socialismo advoga 
pelo estabelecimento de politicas capazes de materializar, expandir e averiguar teses que encaminham outras modalidades de relação de produção e outras formas de suprimento das condições objetivas à autorrealização. A conceituação teórica e finalidade concreta da justiça social, desse modo, ganham horizontes mais ousados e se revelam abertas a concatenar esse conceito normativo a uma pretensão emancipatória mais vigorosa.

Ademais, a perspectiva experimentalista carrega riquezas que tornam plausivel uma interlocução com aquilo que Amy Allen denominou "descolonização da Teoria Crítica" (Allen, 2016). Ao contrário do expediente comum no século XX de se formular - politica e teoricamente - um modelo institucional de socialismo e buscar implementá-lo onde quer que seja, a ideia de experimentação histórica recusa um protótipo universal apriorista de Estado socialista. Admitindo que a liberdade social (também pensada para as relações pessoais e a participação na formação pública da vontade) é necessariamente cosmopolita, o autor entende que sua efetivação concreta deve ser primeiramente enraizada em nível local, de modo que iniciativas diversas, oriundas em contextos dos mais distintos, possam vir posteriormente a se articular e enriquecer mutuamente. Não cabe, nessa concepção, um etapismo teleológico dos modos de produção ou um modelo academicamente formulado no aguardo da oportunidade de sua aplicação. No lugar, diz Honneth:

O socialismo atual, para conseguir uma mobilização político-prática, apesar de toda necessidade de possuir uma articulação e uma organização mundial, dadas as interdependências globais, tem de agir sempre primeiro a nivel local, em campos de referência de ação coletiva razoavelmente transparentes. É por aí que o socialismo tem de começar a tentar conquistar os interessados ao projeto ético que visa libertar as potencialidades presentes na ordem social existentes de uma reciprocidade mais forte e, portanto, de uma concretização futura da liberdade social (HONNETH, 2017, p. 143).

Por conseguinte, uma implicação relevante do argumento está na perspectiva de que os avanços políticos, jurídicos e morais na direção de formas sociais cada vez mais realizadoras da liberdade social tornam necessário o abandono de narrativas sobre "pais fundadores" e sujeitos históricos. Abre, portanto, novos caminhos para diálogo com projetos sociopolíticos fundamentados sobre perspectivas pós-coloniais e decoloniais. Se o socialismo é um projeto mundial cujo modelo não está dado metafisicamente, sua realização 
cosmopolita deve admitir a possibilidade empírica de existirem experiências sociais, na periferia e semiperiferia mundial, reveladoras de caminhos para a ampliação da liberdade. Porque o "desperdício de experiências", para evocar uma expressão de Boaventura de Sousa Santos (2013), não é um problema apenas de ordem teórico-epistemológica, mas efetivamente político: da Via Campesina na América Latina ao Socialismo Africano de Julius Nyerere, passando pelos orçamentos participativos e redes de economia solidária, não faltam exemplares passados e presentes de ações sociopoliticas periféricas que possam contribuir para atualizar a ideia de socialismo. E a obra de Honneth abre espaço para pensar de tal modo essa guinada possivel - e, a seu ver, necessária - para a renovação e descolonização das esquerdas e seus projetos politicos.

Pode-se acusar, decerto, algumas questões mal resolvidas na obra, como a perspectiva do "cidadão" como destinatário fulcral da ideia de socialismo num contexto mundial em que as restrições postas por esse estatuto político são costumeiramente mobilizadas para a exclusão de inúmeras vidas humanas do direito à liberdade. De todo modo, o argumento é bastante satisfatório em seu objetivo principal: demonstrar como o modelo teórico tardio de Axel Honneth pode fundamentar transformações emancipatórias profundas, não limitadas ao quadro institucional das sociedades capitalistas centrais.

\section{Referências}

ALLEN, Amy. The End of Progress: decolonizing the normative foundations of critical theory. New York: Columbia University Press, 2016.

HONNETH, Axel. O Direito da Liberdade. São Paulo: Martins Fontes, 2015. HONNETH, Axel. A Ideia de Socialismo: Tentativa de Atualização. Lisboa: Edições 70, 2017.

SANTOS, Boaventura de Sousa. A Critica da Razão Indolente: contra o desperdicio da experiência. São Paulo: Cortez, 2013. 